\title{
Metazoa Ludens: Mixed Reality Environment for Playing Computer Games with Pets
}

\author{
Roger K. C. Tan, Adrian David Cheok and James K. S. Teh
}

\begin{abstract}
For better or worse, technological advancement has changed the world to the extent that at a professional level demands from the working executive required more hours either in the office or on business trips, on a social level the population (especially the younger generation) are glued to the computer either playing video games or surfing the internet. Traditional leisure activities, especially interaction with pets have been neglected or forgotten. This paper introduces Metazoa Ludens, a new computer mediated gaming system which allows pets to play new mixed reality computer games with humans via custom built technologies and applications. During the game-play the real pet chases after a physical movable bait in the real world within a predefined area; infra-red camera tracks the pets' movements and translates them into the virtual world of the system, corresponding them to the movement of a virtual pet avatar running after a virtual human avatar. The human player plays the game by controlling the human avatar's movements in the virtual world, this in turn relates to the movements of the physical movable bait in the real world which moves as the human avatar does. This unique way of playing computer game would give rise to a whole new way of mixed reality interaction between the pet owner and her pet thereby bringing technology and its influence on leisure and social activities to the next level.
\end{abstract}

Index Terms - Augmented Reality, Game Design and Development, Mixed Reality, Pets Interaction.

\section{INTRODUCTION}

In today's modern world the increasing demands of professionalism have been equated to the huge increased in working hours as compared to yesteryears [1]. The results: the lack of time for simpler pleasures of lives including spending time with pets; pets are more than often left alone at home or neglected by their busy owners. On the other hand, the population (especially the younger generation) has been focusing their attention on the computer either surfing the Internet or playing computer games [2] such that they have neglected their pets in their homes. One of the improvements in

Manuscript Received on October 3, 2006. This work was supported in part by the Mixed Reality Lab, Singapore, a part of the IDM Network in the National University of Singapore.

R. K. C. Tan is with the National University of Singapore (phone: 65 65167514; e-mail: rogerthomastan@mixedrealitylab.org).

Adrian David Cheok is with National University of Singapore. (e-mail: adriancheok@mixedrealitylab.org).

J. K. S. Teh is with the National University of Singapore (e-mail: james.tks@mixedrealitylab.org). society that could improve human social activities is human interaction with pets, as pets can provide companionship, non-judgmental acceptance and love [3] as well as help lower the level of stress and social strain experienced by their owners [4]. As such what arises is the need to bridge the gap between the progressions of our lifestyles and our connection with our pets for the balance of our well being.

Metazoa Ludens was therefore devised with this philosophy, it acknowledges the technological advancement and the augmented lifestyle it gives and marries it with human-pet interaction in a novel mixed reality manner. Metazoa Ludens thus enables playing computer games between humans and animals in a technologically controlled environment. In the system, the pet's play (hamster in this case) is triggered by its impulses for food and its space is 'shared' with their human owners whose presence are acquainted in a very similar way to experiences of the human presence in the worlds of multiplayer online games.

This is a preliminary paper on the Metazoa Ludens, a more intensive user study will be carried out and the findings submitted to SIGCHI. The rest of the paper will consist of the following parts: Metazoa Ludens is therefore devised to address this problem. Section 2 explores the present research and relates the system to the other research works related to this paper. Section 3 talks about the technical details of the system. Section 4 discusses the experiment conducted with Metazoa Ludens and finally Section 5 concludes this paper.

\section{BACKGROUND}

\section{A. Society and Technology}

Technology advancement has made the life of humanity easier, faster and more efficient, not forgetting to mention quality of life has been made better to a great extent. Nonetheless like all issues there are two sides to a coin. Longer working hours are expected in the professional world in order to match up with the higher level of efficiency thus produced by technology [5]. In addition, globalization as advocated by technology has caused an increased in professionals across the globe on business trips [6]. Such huge demand on one's professionalism if left unchecked could result in serious social issues like psychiatric disorders including major depression and alcoholism; health problems like myocardial infarction, diabetes mellitus and hypertension $[1,5]$. 
On a social level, abusive use (be it intentional or accidental) of such technologies among the population (especially the younger generation) sees a huge addiction to computer games and Internet [2]. Such abuse may bring about negative effects on the social life and self confidence of such individuals [7] resulting in socially isolated individuals with increased aggression and decreased self-esteem [8].

On the other hand, for better or worse, the society has now become heavily dependent on advanced technology, there is no way one can retract the use of such technology nor boycott it completely at a professional level. Computer games and Internet use on a social level have integrated into the society as activities taking place in cultural niches, giving rise to complex interaction amongst the computers, the web, gaming cultures and the gamers [9]. It has also matured over the years such that it is no longer an adolescent's plaything (the majority of computer game clientele is very much an adult profile [10]) and positions computer games as serious leisure activities [8].

While acknowledging advanced technology's negative effects one cannot deny its fitful integration into the society. The assessment of such a situation would lead to a conclusion: to embrace and celebrate technology since there is no way to make it go away; yet in an attempt to make the world a better place, leisure technologies thus devised should address and mend (or minimize) the growing gaps within the society caused by isolation deprived from advanced technology.

The next section digs into human-pet interaction and examines the possibility of mending the gaps (as mentioned in previous paragraph) with human-pet interaction in technological devices.

\section{B. Human-Pet Interaction}

Animals have been part of the human's life since eons ago, we made use of animals to work for us like those that pulled the carts or ploughed the fields. Currently animals in urban life are being kept as domesticated household pets for companionship and unconditioned love and attention. Similarly like human beings, pets have a sense of belonging, experience pain and need love [11]; once adopted they are mostly dependent on their human owners for their livelihood, sense of well being, protection and love. In the increasing pace of life in the modern world as brought forth by advancement in technology, such responsibility are generally neglected and taken for granted by the pets' owners [12].

Unbeknownst to most such negligence of pets may be more of a losing end to the owners than the pets. As discussed in the previous section, there are ill effects of technology on the society. On the other hand pets are capable of satisfying human being's need to nurture, providing social support and unconditioned attention and love to their human owners [11], suggesting that they might be (to a certain degree) able to counteract the negative aspects of technological advancement.

Children's self-esteem scores have been reported to have increased significantly over a period of time of keeping pets in their school classroom [13]. Parents do admit as well that pets proved to be extremely useful in educating children about life events [14]. In addition pets do provide companionship and help reduce level of loneliness among their owners who interact frequently with them [15] while another study shows that interaction with pets help reduce stress and anxiety level among their owners [16].

On a physiological health level, human-pet interactions (dogs in this case) are able to help reduce the level of blood pressure of the owners thereby reducing the risk of hypertension [17]. In addition, interaction with pets (termed "pet effect" in this case) is found out to be beneficial to the cardiovascular conditions of the pets' owners [18] and bring about a significant reduction in minor health problems for their owners [19].

All in all one negative aspect of technological advancements is the negligence of pet owners with respect to their interaction with their pets [12], yet with this simple inattentiveness a great number of positive consequences (as depicted above) are foregone. Without compromising on the actualities of technological sophistication, Metazoa Ludens is developed (to be added on to the ranks of leisure technology): by incorporating human-pet interaction it not only aims to evolve the ties and bonds humans share with animals it also aims to bring leisure technology to the next level which has positive effects on the users and is capable of the betterment of the quality of life.

The next section moves into the various pre-existing works on interactive systems (human-pet interaction as well as remote interaction) and attempts to position Metazoa Ludens amongst them.

\section{Human-Pet Interactive System and Mixed Reality Interactive System}

Current human-pet interaction between pet owners and their pets mostly involved simple games to the likes of fetch, toying with a ball of yarn or chasing squeaky rubber toys; a more established tool-based interaction used for training dogs known as clicker training [20] uses a click sound made just before a treat is given. This is used to condition dogs into understanding that whenever a click sound is heard a treat would not be far away. This is subsequently used to encourage desirable behaviors from the pet dogs by clicking whenever wanted behaviors are performed. Nonetheless all these game plays with pets are simple and do not utilize the enriching experience that sophisticated high-tech de-vices like video game systems (Xbox, Playstation) are capable of giving.

Alternatively sophisticated works done on human-pet interaction mostly involve non-living electronic/virtual pets like AIBO [21], Tamagotchis [22] and Furby [23] which have been created to augment the human-pet interaction process by making use of technological devices to give a more enriching experience. Other uses of such robotic pets have been developed like Sekiguchi [24] who introduced a robotic teddy bear for interpersonal communication and Druin [25] who proposed a robot animal that is capable of telling stories to children.

In addition even though it was found out that robotic pets 
like AIBO are capable of providing the elderly with physiological, emotional and cognitive relief, the companionship is still not the same as that shared by human and real pets [26].

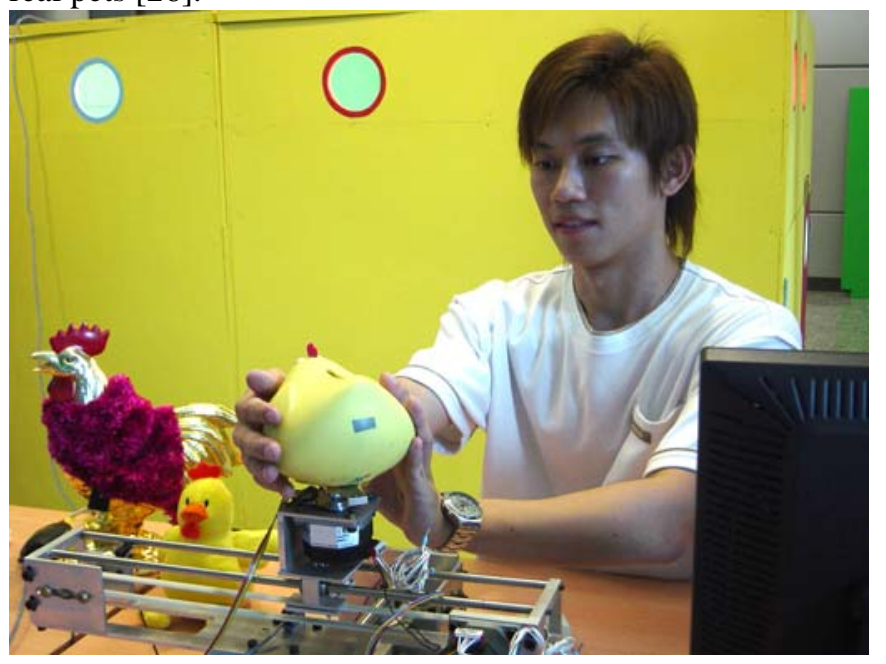

Fig.1. Poultry.Internet: a remote human-pet haptic interactive system. See Color Plate 16.

All in all it can be seen that despite robotic/virtual pets are able to reach a certain level of likeness to real pets they are still not capable of totally replacing a real live pet companion. The complex interaction between live pets and human owners go far beyond what can be achieved by programming bits and bytes. Hence there is a need to create a breakthrough system such as Metazoa Ludens that is capable of greatly enhancing the interactivity between pet and their human owners.

As mentioned previously the advancement of the modern world has brought pet owners away from their homes, spending hours at work either in office or overseas business trips away from their pets. This uncovered the need to incorporate mixed reality interactivity into the human-pet interaction system. Related mixed reality interaction systems include Human Pacman [27] and Can You See Me Now [28] which using mixed reality techniques provides a pervasive gaming environment linking players over distances. Sports over Distance [29] were developed as extension to tangible user interface called exertion interface and was used for remote physical interaction and communication through sports play. Such systems describe a bidirectional way for remote interaction and pervasive game-play; nonetheless these systems only take human-human interactions into consideration without consideration of human-pet inter-actions.

Poultry.Internet [12] on the other hand is developed for remote human-pet (chicken in this case) interactions through the Internet (see Fig. 1.). Pet owners can pat their pet chicken while away in office or business trips through the Internet via a pet jacket which the pet chicken is wearing. This is the first ever known remote haptic human-pet interaction ever done. Building upon Poultry.Internet, Metazoa Ludens extends and augments this by allowing pet owners to interact with their pets via playing computer games (either locally or remotely) with them.
Hence it can be seen that Metazoa Ludens filled in the niche which has been lacking, to provide a way to interact with our live pets, locally or remotely, by playing games with them while making use of high-technological advancements to create a computer gaming environment so as to augment and enhance such interactivity.

Having explored the current technical situation related to Metazoa Ludens the next section moves on to explore and understand the situation from a pet's perspective so as to create an environment most suitable for the pets' well being.

\section{Pets behaviour}

Metazoa Ludens was conceived with an aim of evolving the ties and bonds humans share with pets; by incorporating latest technological advancement Metazoa Ludens aims to pave way for a revolutionary manner for human-pet interaction in the name of leisure technology. Hence in addition to innovative use of technology pets' behaviour must be understood to prevent a situation whereby instead of empowering the pets they get caught up in a compromised situation.

Pets need love and care from their owners [11] as well as a good dose of exercise with suitable diet to ensure healthy living [30]. Metazoa Ludens by providing a way to interact with pets locally or remotely is capable of allowing owners to shower their pets with attention; in addition the element of exercise may be incorporated into the system to add yet another beneficial feature for the pets.

In exploring the use of exercise for the pets, the pets may not be motivated to exercise or even understand the need to for it. Positive reinforcement onto the pets upon them performing a desirable action (better known as operant condition [31]) may be used. Due to the powers of operant conditioning it forms the basis for multimillion dollars based business for training animals for movies and shows [32]. It has also been used to identify what animals "like" and what they "do not like" [33].

Conclusively besides being a system which allows humans to interact with their pets in an innovative way, Metazoa Ludens should incorporate beneficial aspects (such as exercises) to the pets with a built-in method of positive reinforcement, to motivate the pets into performing positive behaviors.

\section{METAZOA LUDENS}

\section{A. System Overview}

The overall system is discussed first to give a clear overview before diving into the intimate details which make up the system.

As shown in Fig. 2, in the real world within the tank of the system, the pet (hamster in this case) chases after a physical movable bait on a moldable surface area. The movement of the hamster is then translated into the movement of a pet avatar in the virtual gaming space which is shared by the pet owner. The pet owner controls the movement of a human avatar in the virtual gaming world, which is actually controlling the movement of the physical bait in the real world. Thus, this loop 
enables the merging of two realities, both pet owner's reality and the pet's reality, either locally or remotely via Metazoa Ludens system.

The physical structure itself has an area of $0.8 \mathrm{~m}$ by $0.8 \mathrm{~m}$ and is $1.5 \mathrm{~m}$ in height. Inside the structure an infra-red camera is placed at the top for tracking of the pets' movements above a mechanical driven arm that makes up the movable bait. The surface which the pets scamper upon is a highly moldable latex sheet molded by sixteen actuators (electric motor driven) placed directly beneath them.
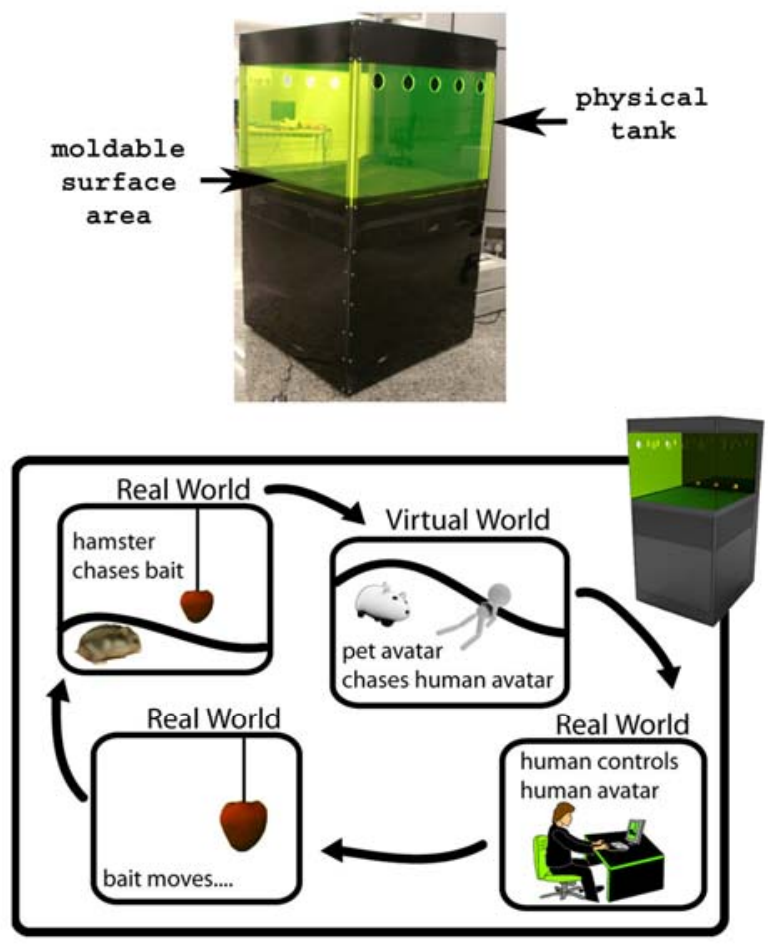

Fig. 2. Overview of Metazoa Ludens.

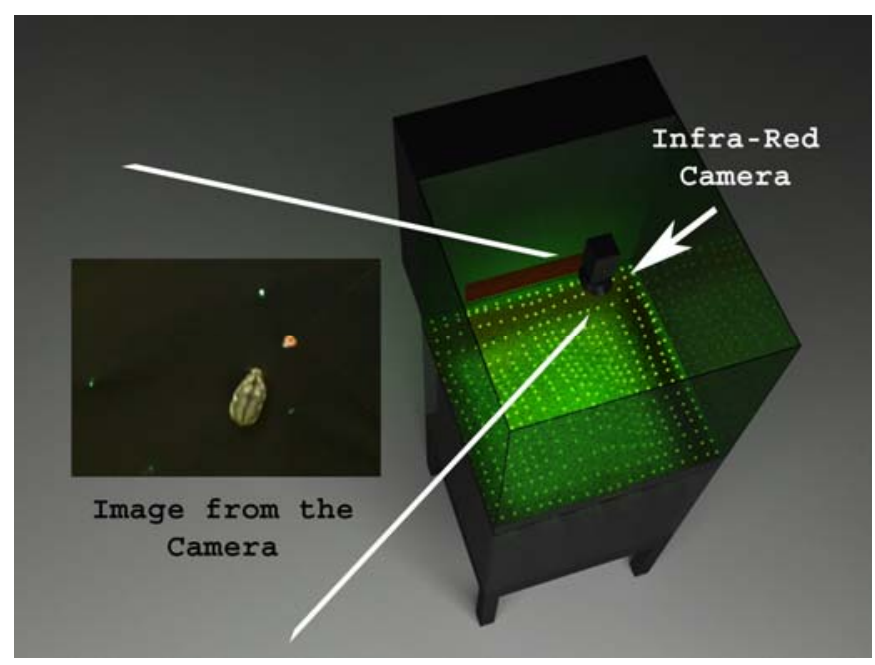

Fig.3. Infrared camera tracking system. See Color Plate 17.

\section{B. System}

The game-play for the pets occurs within a tank in the structure of the system. As the pet moves on the surface its movements are tracked using infra-red camera tracking system (see Fig. 3) and translated into virtual reality coordinates for the pet avatar. This allows a real-time update of the pet avatar's movement in the virtual game world in correspondence to the actual movements of the pet.

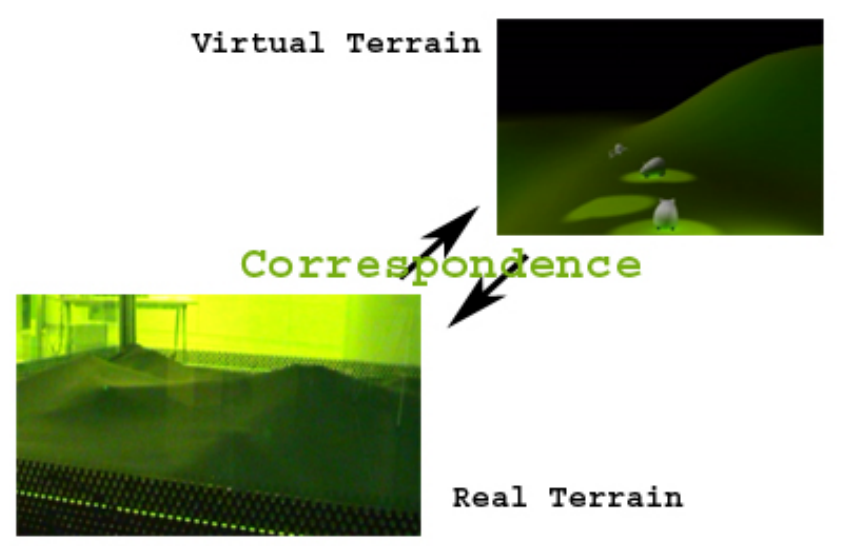

Fig.4. Moldable surface which corresponds to the changing terrain in the virtual world.

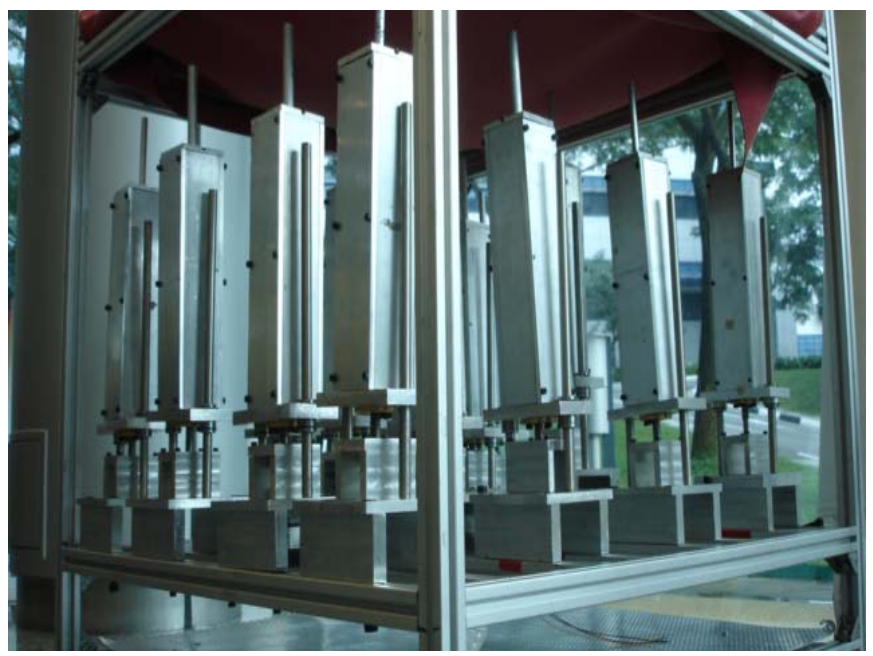

Fig.5. Mechanical actuators below the moldable surface.

The moldable surface in which the pets run upon corresponds to the changing terrain in the virtual world (see Fig. 4). This is achieved using a highly elastic latex surface stretched over mechanical actuators driven by electric motors (see Fig. 5). Data from the system are sent to the motor controllers through wireless Bluetooth technology which then cause movements of the individual actuators under various points of the latex surface. This same data is simultaneous used by the system to update the terrain within the virtual world in order to create a corresponding landscape for the game-play. The pet owner controls a human avatar within the virtual world, flying across the changing terrain and escaping from the pet avatar (see Fig. 6). The system will take this input from the pet owner to not only update the human avatar in the virtual world in real-time but update the position of the real movable bait in the tank (see Fig. 7). This input is transmitted from the system wirelessly using Bluetooth technology to the motor controller of the mechanical sliders for the movable bait. The movable 
bait will then move accordingly as controlled.

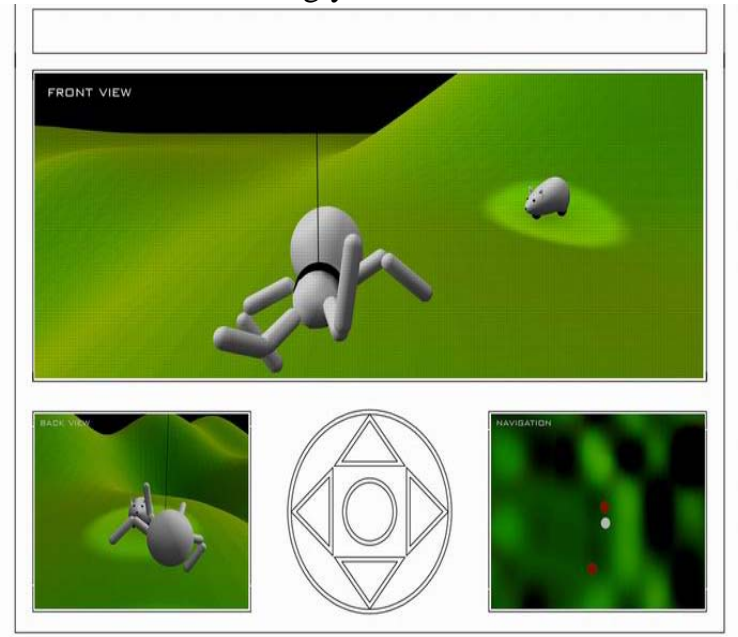

Fig. 6. Human avatar escaping from pet avatar. See Color Plate 18.

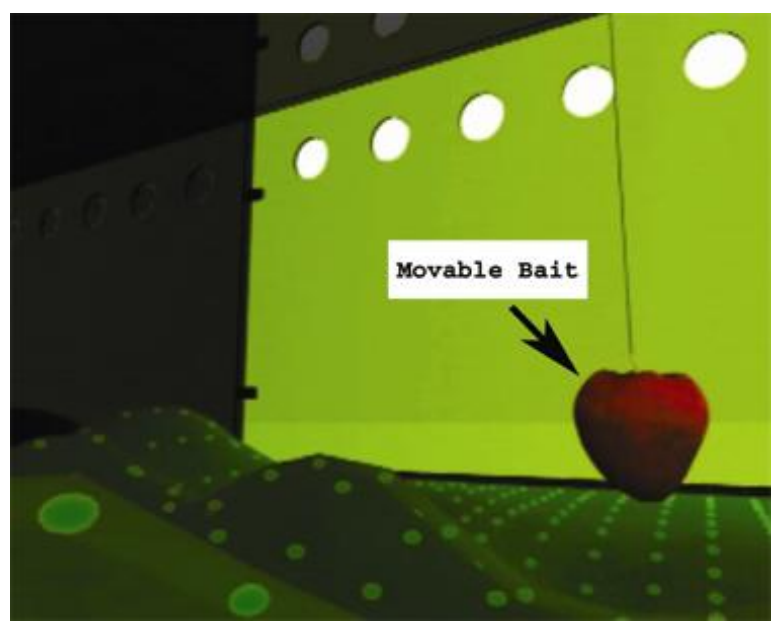

Fig. 7. Movable bait in the tank, corresponding to the human avatar movement in virtual world. See Color Plate 19.

\section{FUTURE WORK}

A pilot test could be conducted to test the system and the use of pets with the system in order to identify any requirements for modifications and adjustments to the system. The well being of hamsters may be measured using a body condition score (BCS) [30]. This will allow the analysis of the system with respect to the hamsters' welfare and com-fort level with regards to using the game. In addition user survey may be carried out to evaluate Metazoa Ludens sys-tem as a game by breaking down the system using features as described by Game Flow model [34] (which in turn is based on Csikszentmihalyi's FLOW theory). This will allow evaluation of the pet owners' enjoyment in the game.

Other possible computer games with pets may be made possible, like Jellyfish Trone whereby the movements of the jellyfish may correspond to that of the worm/snake in the Trone-like game environment and Chicken Pacman whereby movements of real chicken walking in a real maze corresponds to the movements of the ghost in the virtual world chasing after the pacman controlled by a human player. This would allow varied human-pet interactions with different types of pets enhanced by technology.

\section{CONCLUSIONS}

The apparent implication for this work would be a novel way for pet owners to interact with their pets through com-puter game-play. It is expected that the work of this project shall kick start an entire new field for both pets and humans within the realms of gaming, media and leisure technology. There are no other examples with computer games being created for play between pet owners and their pets. Thereby, this project would create a whole new area for exploration for human-pet interaction and leisure technology.

\section{ACKNOWLEDGEMENT}

The authors would like to thank all members of Mixed Reality Lab, Singapore, for their help rendered.

\section{REFERENCES}

[1] M. Shields. Long Working Hours and Health. Health Reports (Statistics Canada, Catalogue no. 75-001-XPE), vol.11, no. 2, autumn 1999.

[2] N. L.Warden, J. G.Phillips and J. R. P.Ogloff. Internet Addiction. Psychiatry, Psychology \& Law, vol. 11, no. 2, pp. 280-295, 2004

[3] C. J. Soares. The companion animal in the context of the family system, Marriage and Family Review, 8, pp. 49-62, 1985.

[4] W. E. Broadhead, B. H. Kaplan, S. A. James, E. H. Wagner, V. I. Schoenbach, R. Grimson, S. Heyden, G. Tibblin and S. H. Gehlbach. The epidemiologic evidence for a relationship between social support and health, American Journal of Epidemiology 117, pp.521-537, 1983.

[5] N.Kawakami, T. Haratani. Epidemiology of Job Stress and Health in Japan, Review of Current Evidence and Future Direction. Industrial Health, vol. 37, pp.174-186,1999

[6] J.Selmer. Expatriate Management: New Ideas for International Business, Greenwood Publishing Group, Westport CT, 1995.

[7] D. M. Griffiths. Does Internet and Computer "Addiction" Exist? Some Case Study Evidence, CyberPsychology \& Behavior, vol. 3, no. 2, pp.211-218, 2000.

[8] J. Bryce and J. Rutter. Gender dynamics and the social and spatial organization of computer gaming, Leisure Studies, vol. 22, no. 1, pp.1-15, 2003.

[9] S. G. Yates and K. Littleton. Understanding Computer Game Cultures, A situated approach. Information, Communication \& Society, vol. 2, no. 4, 1999, 566-583.

[10] D. M. Griffiths, M. N. O. Davies and D.Chappell. Breaking the Stereotype: The Case of Online Gaming, CyberPsychology \& Behavior, vol. 6, no. 1, pp.81-91, 2003.

[11] S. Phaosavasdi, S. Thaneepanichskul, Y.Tannirandorn, M. Thamkhantho, C. Pruksapong, A. Kanjanapitak and H. Leong. Animals and Ethics, Journal of Medical Association of Thailand, vol. 88, no. 2, pp.287-293, 2005.

[12] S. P. Lee, A. D. Cheok, K. S. Teh, P. L. Goh, W. J. Chio, C. Wang and F.Farbiz. A mobile pet wearable computer and mixed reality system for human-poultry interaction through the internet, Special Issue of Personal and Ubiquitous Computing: Multi-modal Interaction with Mobile and Wearable Devices, Mar 2006, pp. 1 - 17, 2006.

[13] F. Bergesen. The effects of pet facilitated therapy on the self-esteem and socialization of primary school children, Proceedings of 5th International Conference on the Relationship between Humans and Animals, 1989.

[14] B. Levinson. The child and his pet: A world of non-verbal communication, Ethnology and Non-verbal Communication in Mental Health, Pergamon Press, Oxford, pp.63-83, 2001. 
[15] M. M.Calvert. Human-pet interaction and loneliness: a test of concepts from Roy's adaptation model, NCBI, vol. 2, 2004, pp.194-202, 1989.

[16] C. C.Wilson. The pet as an anxiolytic intervention. NCBI, PubMed, vol.179, no.8, pp.482-9, 1991.

[17] E. Friedmann, A. H.Katcher, S. A. Thomas, J. J.Lynch, and P. R.Messent, Social interaction and blood pressure, Influence of animal companions. NCBI, PubMed, vol.171, no.8, 461-5, 1983.

[18] J. K. Vormbrock and J. M. Grossberg, Cardiovascular effects of human-pet dog interactions. Journal of Behavioral Medicine, pp.509-517, 1988.

[19] J. Serpell. Beneficial effects of pet ownership on some aspects of human health and behaviour. Journal of the Royal Society of Medicine, vol.84, no.12, pp.717-720, 1991.

[20] B. Resner, Rover@home. Masters thesis, MIT, 2001.

[21] M. Fujita, H. Kitano and K. Kageyama. Reconfigurable physical agents, Proceedings of 2nd International Conference of Autonomous Agents, pp.54-61, 1998.

[22] D. Behrens. Keeping up with the tamagotchis/a report on virtual pets and knockoff reality, Newsday, 1997.

[23] K. Hafner and T. Cenicola. As robot pets and dolls multiply, children react in new ways to things that are almost alive, The New York Times, 1999.

[24] D. Sekiguchi, Robotphone. RUI for interpersonal communication, In SIGGRAPH 2001 Emerging Technology, pp.134, 2001.

[25] A. Druin. Designing pets: a personal electronic teller of stories, In Proceedings of the CHI 99 Conference on Human Factors in Computing Systems, pp.326-329, 1999.

[26] S. Turkle. People who like fake dogs all things considered. Interview with Sherry Turkle of MIT Media Labs, Discusses relationships with Sony's AIBO and other 'computational objects', May 11, 2001.

[27] A. D. Cheok, K. H. Goh, W. Liu, F. Farbiz, W. F. Siew, S. L. Teo, Y. Li and X.Yang. Human Pacman: a mobile, wide-area entertainment system based on physical, social, and ubiquitous computing, Personal and Ubiquitous Computing, vol. 8, no. 2, SpringerLink London, pp.71-81, 2004.

[28] M. Flintham, S. Benford, R. Anastasi, T. Hemmings, A. Crabtree, C. Greenhalgh, N. Tandavanitj, M. Adams and J. Row-Farr. Where on-line meets on the streets: experiences with mobile mixed reality games, In Proceedings of SIGCHI Conference on Human Factors in Computing Systems, pp.569-576, 2003.

[29] F. Mueller, S. Agamanolis and R. Picard. Exertion interfaces: sports over a distance for social bonding and fun, ACM Press New York, NY, USA, 2003.

[30] T. Estra. No more fat pets: canine and feline obesity, how to win, Cornell University, Seminar SF610.1 2003 E88, 2003.

[31] B. F. Skinner. The Behavior of Organisms, Appleton-Century-Crofts. New York, 1938.

[32] F. K. McSweeney. Making Sense of Animal Conditioning, Symposium of Grazing Behaviour of Livestock and Wildlife, 1999.

[33] T. M. Foster, W. Temple and A. Poling. Behavior analysis and farm animal welfare. Behav. Analyst, 1997, 20:87-96.

[34] P. Sweetser and P. Wyeth. GameFlow: A Model for Evaluating Player Enjoyment in Games, Computers in Entertainment, vol. 3, no. 3, ACM, 2005.

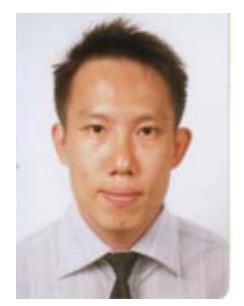

Roger K. C. Tan is a $\mathrm{PhD}$ research scholar in the Mixed Reality Lab, National University of Singapore. His work has been published on several conferences and journals such as: LASTED, ICUTE and SWITCH and include flash presentations which won 1st runner-up, beating 65 other countries, in the Annual International L'Oreal Marketing Awards held in Paris, June 2004.

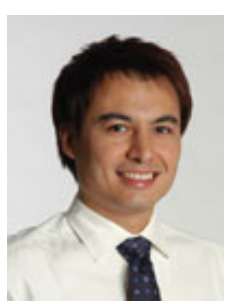

Adrian D. Cheok is Director of the Mixed Reality Lab, National University of Singapore. He is Associate Professor in the Department of Electrical and Computer Engineering. He has previously worked in real-time systems, soft computing, and embedded computing in Mitsubishi Electric Research Labs (Osaka, Japan) and NUS. He has been working on research covering mixed reality, human-computer interaction, wearable computers and smart spaces, fuzzy systems, embedded systems, power electronics, and multi-modal recognition. He has successfully obtained funding for four externally funded projects in the area of wearable computers and mixed reality from the Defense Science Technology Agency Singapore. The research output has included numerous high quality academic journal papers, research prototype deliverables to DSTA, numerous demonstrations including to the President and Deputy Prime Minister of Singapore, CNN / CNBC television worldwide broadcasts on his research, and international invited new media exhibits such as Ars Electronica. He is currently an Associate Professor at the National University of Singapore where he leads a team of over 20 researchers and students. He has been a keynote and invited speaker at numerous international and local conferences and events. He is invited to exhibit for two years in the Ars Electronica Museum of the Future, launching in the Ars Electronica Festival 2003. He was IEEE Singapore Section Chairman 2003, and is presently ACM SIGCHI Chapter President. He was awarded the Hitachi Fellowship 2003, the A-STAR Young Scientist of the Year Award 2003, and the SCS Singapore Young Professional of the Year Award 2004. In 2004 he was invited to be the Singapore representative of the United Nations body IFIP SG 16 on Entertainment Computing and the founding and present Chairman of the Singapore Computer Society Special Interest Group on Entertainment Computing. Also in 2004, he was awarded an Associate of the Arts award by the Minister for Information, Communications and the Arts, Singapore.

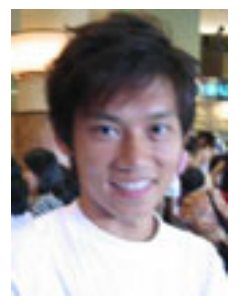

James K. S. Teh is a Masters Research scholar in the Mixed Reality Lab, National University of Singapore. He was previously a recipient of the ASEAN scholarship and has authored and co-authored several conference papers and journal, for example, Personal and Ubiquitous Computing, ICAT and also won an art award at the prestigious VIDA 8.0 Art \& Artificial Life International Competition, Fundación Telefónica. 